\title{
Biological rationale for the use of PPAR $\gamma$ agonists in glioblastoma
}

\author{
Hayley Patricia Ellis ${ }^{1}$ and Kathreena Mary Kurian ${ }^{2}$ * \\ ' School of Cellular and Molecular Medicine, University of Bristol, Bristol, UK \\ ${ }^{2}$ Brain Tumour Research Group, Institute of Clinical Neuroscience, University of Bristol, Bristol, UK
}

\section{Edited by:}

Michele Caraglia, Second University

of Naples, Italy

Reviewed by:

Giovanni Vitale, Università degli Studi di Milano, Italy

Carsten Carlberg, University of

Eastern Finland, Finland

*Correspondence:

Kathreena Mary Kurian, Brain Tumour

Research Group, Institute of Clinical

Neurosciences, Frenchay Hospital,

Frenchay Park Road, Bristol BS16

1LE, UK

e-mail: kathreena.kurian@nbt.nhs.uk
Glioblastoma multiforme (GBM) is the most common primary intrinsic central nervous system tumor and has an extremely poor overall survival with only $10 \%$ patients being alive after 5 years. There has been interesting preliminary evidence suggesting that diabetic patients receiving peroxisome proliferator-activated receptor gamma (PPAR $\gamma$ ) agonists, a group of anti-diabetic, thiazolidinedione drugs, have an increased median survival for glioblastoma. Although thiazolidinediones are effective oral medications for type 2 diabetes, certain agonists carry the risk for congestive heart failure, myocardial infarction, cardiovascular disease, bone loss, weight gain, and fluid retention as side-effects. The nuclear receptor transcription factor PPAR $\gamma$ has been found to be expressed in high grade gliomas, and its activation has been shown to have several antineoplastic effects on human and rat glioma cell lines, and in some instances an additional protective increase in antioxidant enzymes has been observed in normal astrocytes. At present, no clinical trials are underway with regards to treating glioma patients using PPAR $\gamma$ agonists. This review presents the case for evaluating the potential of PPAR $\gamma$ agonists as novel adjuvants in the treatment of refractory high grade glioma.

Keywords: glioblastoma multiforme, PPAR gamma, brain tumour, thiazolidinediones, glioma

\section{INTRODUCTION}

The PPARs are ligand-inducible transcription factors of the nuclear receptor superfamily (1). There are three PPARs expressed in mammalian tissues: PPAR $\alpha$ is primarily expressed in the heart, liver, and brown adipose tissue; $P$ PAR $\beta / \delta$ is ubiquitously expressed; and PPAR $\gamma$ is most highly expressed in white and brown adipose tissue (2).

The PPARs control complex gene expression involved in lipid metabolism and adipogenesis, as well as inflammation, and metabolic homeostasis (3). Under healthy conditions, PPARs are primarily receptors for dietary fats such as oleic, linoleic, and linolenic acids, and also bind diverse lipid metabolites, for example prostaglandin J2, 8S-hydroxyeicosatetraenoic acid, and oxidized phospholipids (4). Ligand binding induces a conformational change in the receptor that allows modulation of PPAR activity via differential recruitment of cofactors and histone modification enzymes. For a detailed account of PPAR $\gamma$ signaling and metabolism, see the review by Ahmadian (5).

Recent studies using high throughput genome-wide transcriptional regulation techniques have now revealed the comprehensive distribution of binding-sites of PPAR $\gamma$ in adipocytes and macrophages (6). PPAR $\gamma$ has been found to be key for adipocyte differentiation using PPAR $\gamma$ knockout mice, which are entirely devoid of adipose tissue (7). All PPARs have been isolated from both developing and adult brain tissue (8), and it has been postulated that activation of the PPAR pathway could have a role in determining neuron viability in the developing midbrain (9).

$\operatorname{PPAR} \gamma$ has two isoforms due to differential promoter usage and alternative splicing: PPAR $\gamma 1$ which is expressed in many tissues and PPAR $\gamma 2$, which under normal conditions is present in adipose tissue, but can be induced by a high fat diet to be expressed in other tissues. PPAR $\gamma$ forms a heterodimer with retinoid-Xreceptor (RXR) to bind ligand efficiently, after which the receptor ligand complex binds DNA and induces signal transactivation (10) (see Figure 1).

\section{PPAR $y$ IN NEOPLASIA}

A recent retrospective clinical review by Grommes showed that diabetic GBM patients treated with PPAR $\gamma$ agonists exhibited an increased median survival of 19 months compared to patients receiving the standard treatment for GBM alone, for whom median survival was 6 months (11). However, the group of patients eligible for statistical analysis was small so the negative correlation between PPAR $\gamma$ agonist use and GBM development was not found to be significant (11). A study has been conducted to determine whether there is a somatic mutation of the PPARG gene with high penetrance that might play a role in the development of GBM (12). Although no high penetrance mutations were found, two polymorphisms were identified, one at codon 12 $\left(P P A R G^{P 12 A}\right)$ and the other at codon $449\left(P P A R G^{H 449 H}\right)$ of the $P P A R G$ gene, and these were found to be highly over-represented in patients with GBM when compared to the matched control group (12). Thirty-three percent of the GBM patients were found to be heterozygous for the $P P A R G^{P 12 A}$ allele (a CCA to GCA polymorphism causing a change from proline to alanine) (12). The $P P A R G^{H 449 H}$ polymorphism (a CAC to CAT change, though the amino acid remains a histidine) appeared to have much higher levels of over-representation, as it demonstrated homozygous 


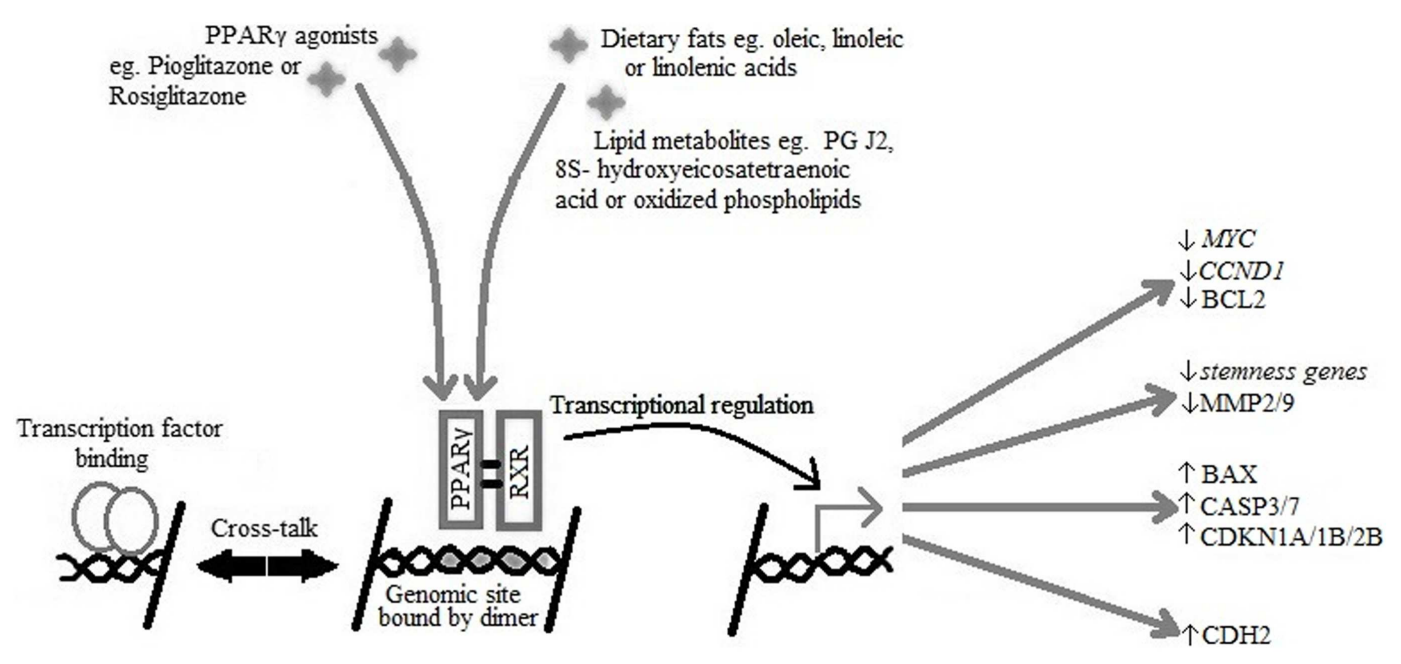

FIGURE 1 | PPAR $\gamma$ and RXR heterodimer binding to the PPAR $\gamma$ genomic binding site in DNA causing transcriptional activation of target genes active in cell-cycle arrest, reduced expression of stemness markers, initiation of apoptosis, and re-differentiation.

expression in $50 \%$ of GBM patients and only $12 \%$ of the control group (12).

The study was repeated with German participants and no deviation was found from the normal representation in the population of either polymorphism (12). However, this could be explained by the variants in the original study being in a linkage disequilibrium, which would be corollary to the founder effect with a relatively new founding allele (12). Preliminary analysis of the PPARG $G^{P 12 A}$ and PPARG $G^{H 449 H}$ polymorphisms found that there was no over-representation or under-representation of these alleles in patient populations with other types of cancers (e.g., melanoma or breast), which suggests that the effect is specific for glioma (12).

PPAR $\gamma$ expression has been described in a range of other neoplasias including colon, lung, prostate, bladder, breast, duodenal, and thyroid (13-19). Interestingly in colon cancer there are differing older reports as to the effect of PPAR $\gamma$ agonists. Some in vitro studies describe differentiation, reduction of malignancy, and inhibition of anchorage-independence in colon cancer (20) whereas in other mouse models enhancement of polyp formation has been observed (21). It has been put forward by Sarraf et al. (13) that PPAR $\gamma$ exhibits tumor suppressive activities in colon cancer because several functionally deleterious $P P A R G$ mutations have been found in cases of sporadic colon cancer. However, in the case of colon cancers with known deletions in the APC (adenomatous polyposis coli) tumor suppressor gene, PPAR $\gamma$ agonists appear to promote tumor growth, and increase the number of colon polyps, possibly by increasing the uptake of dietary fat (21). In human bladder cancer, PPAR $\gamma$ agonists troglitazone and $15 \mathrm{~d}-$ PGJ2 have shown to inhibit tumor growth (22). By contrast, in an investigation in rats of the effect of Naveglitazar, a PPAR $\alpha / \gamma$ dual agonist showed a significant increase in bladder neoplasms. (23). In another study to determine if rosiglitazone had chemopreventive activity, female rats were treated with different doses of rosiglitazone plus a urinary bladder-specific carcinogen, and it was found that larger cancers developed compared with rats treated with the bladder carcinogen alone (24). However, no apparent activity of rosiglitazone as a complete carcinogen was observed. (24). Additionally, the effects were only recorded in females and it was postulated that this could be due to irritant effects. However, the effects were observed rapidly after administration with rosiglitazone, contesting a long-term chemical irritant effect (24).

It is important to mention that many of the carcinogenic effects of the agonists for the nuclear receptor PPAR $\gamma$ are highly species specific; i.e., observed in rodents but not humans or other higher order mammals.

\section{CURRENT RESEARCH INTO PPAR $\gamma$ AGONISTS AND GLIOBLASTOMA MULTIFORME BRAIN TUMOR GROWTH INHIBITION}

One of the important hallmarks of cancer is a proliferative advantage over normal tissue. One possible mechanism by which PPAR $\gamma$ agonists can inhibit cell proliferation is by induction of cell-cycle arrest in G0/G1 phase (25-27), and a reduction of the proportion of cells entering S-phase $(25,27)$. In concordance with this finding, decreased levels of MYC have also been detected upstream of the S-phase transition $(25,28)$, as well as possible down-regulation of CCND1 (cyclin D1) and associated cyclin-dependent kinases $(25,28)$. The decreased proportion of cells entering S-phase in response to PPAR $\gamma$ agonists has also been linked to up-regulation of the cyclin-dependent kinase inhibitors CDKN1A, CDKN1B, and CDKN2B $(25,27)$.

PPAR $\gamma$ agonists have also been found to inhibit the expansion and proliferation of $\mathrm{CD}_{133^{+}}$brain tumors stem cells (BTSCs, also termed Brain Tumor Initiating Cells) by inhibiting the Janus kinase/signal transducer and activator of transcription (JAK/STAT) pathway using ciglitazone, 15-deoxy- $\Delta 12,14$ prostaglandin J2 (15d-PGJ2), and all-trans retinoic acid (ATRA) $(26,29)$. 
JAK/STAT signaling is particularly important in the antitumor activity of PPAR $\gamma$ agonists because the inhibition of JAK2 (upstream regulator of STAT3) has been shown to have a role in slowing the disease progression of GBM in vivo and in vitro models (30), and troglitazone has been described as an antagonist for STAT3 signaling (31). Antagonists for the JAK/STAT pathway work by phosphorylating tyrosine 705 of STAT3 leading to downregulation of CCND1 and BCL2L1 (B-cell lymphoma protein 2 extra large) which act to push cells through the cell-cycle and prevent apoptotic cell death (30). High levels of STAT3 signaling have been noted in BTSCs, and inhibition of this has been shown to decrease BTSC resistance to temozolomide (32), which is promising with regards to use of PPAR $\gamma$ agonists as an adjuvant therapy in GBM. Glioma cell lines have been found to have a much higher rate of cellular metabolism, which can be significantly increased by addition of troglitazone (33). Therefore, glioma cells will suffer nutrient deprivation and could be more susceptible to cytotoxic killing than normal astrocytes (33), an effect which is thought to be mediated by reactive oxygen species produced by mitochondria (34).

\section{GLIOMA CELL DIFFERENTIATION}

One of the ways that PPAR $\gamma$ could counteract the malignant properties of BTSCs is via regulation of genes involved in maintaining a stem cell state termed "stemness genes" as well as differentiation. This is important in the cases of grade III and IV glioma, as the BTSCs may be responsible for the recurrence and growth of the malignant tissue through mechanisms such as self-renewal $(35,36)$.

Many stemness genes have been found to be down-regulated by activation of the PPAR $\gamma$ pathway by the agonists ciglitazone and 15-PGJ2, though ATRA treated cells showed no significant difference. An example of a stemness gene down-regulated by PPAR $\gamma$ agonists is SOX2, which is important in maintaining pluripotency in stem cells, and plays a role in repressing neural differentiation as it is over-expressed in BTSCs but remains at low levels of expression in normal tissue (37). In studies assessing the decrease in expression of stemness genes, mouse neural stem cells were cultured using epidermal growth factor and basic fibroblast growth factor to stimulate expression of stemness markers, and the changes in levels of expression were analyzed using TaqMan low density gene arrays following treatment with PPAR agonists $(35,36)$. Most stemness genes monitored exhibited down-regulated expression; however expression of NOG appeared to be up-regulated, possibly because it is involved in neurogenesis and developmental patterning of the brain across the anterior-posterior axis (38). It has been suggested that the change in expression of stemness genes means that PPAR $\gamma$ agonists can modulate differentiation via regulation of stemness factors $(35,36)$.

Another way that PPAR $\gamma$ has been found to regulate differentiation of neural stem cells is by inducing expression of differentiation genes $(35,36)$. Expression of differentiation markers was also analyzed in similar experiments to those described above, and it was found that PPAR $\gamma$ agonists increased expression of glial cell markers in T98G and DB29 BTSCs. Compared to a dimethyl sulfoxide control, ciglitazone, ATRA, and 15d-PGJ2 all resulted in an increased expression of genes such as GFAP (glial fibrillary acidic protein) and TUBB3 ( $\beta$ III-tubulin), specific to neuronal cells $(35,36)$. Also, human and rat cell lines treated with PPAR $\gamma$ agonists have been found to transiently increase their expression of $\mathrm{CDH} 2$ (N-cadherin), a neural differentiation marker, as well as showing outgrowth with a morphology similar to that of normal astrocytes (39). This suggests that activation of the PPAR $\gamma$ pathway can control differentiation of neural progenitor cells via modulating expression of neural differentiation genes as well as those involved in maintaining pluripotency $(35,36)$.

\section{REDUCTION OF LOCAL INVASIVENESS}

Another effect of PPAR $\gamma$ agonists on glioma tissue is to reduce local tissue invasiveness $(28,40,41)$. Invasion of malignant cells into nearby healthy brain tissue in glioma patients may be mainly mediated by matrix metalloproteinases MMP-2 and MMP-9 which exhibit elevated expression in tumor progression (42). MMP2 and MMP-9 expression has been monitored before and after administration of pioglitazone using immunohistochemical assays $(40,41)$. Both MMP-2 and MMP-9 have independently been found to be down-regulated after treatment with pioglitazone, suggesting the role of PPAR $\gamma$ agonists in reducing glioma cell invasiveness $(28,40,41)$. Also, as differentiation marker expression increases in expression after addition of PPAR $\gamma$ agonists, this implies that the cellular phenotype becomes less invasive via differentiation as well as reduction of expression of malignant cell markers (41).

Pioglitazone has also been found to reduce CTNNB1 $(\beta$ catenin) expression without changing its cellular localization (28). CTNNB1 controls the expression levels of CDH1 (E-cadherin) to mediate cellular attachments and is often over-expressed in high grade glioma when compared to low grade or normal tissue (43). This is a possible mechanism by which reduction of CTNNB1 expression by PPAR $\gamma$ agonists could contribute to inhibition of the loss of cellular attachments, as well as reducing the transcription of tumor-promoting target genes of CTNNB1 such as CCND1 and MYC (28).

\section{INDUCTION OF APOPTOSIS}

One of the most well understood responses of glioma cells to $\operatorname{PPAR} \gamma$ agonists is a reduction of cellular viability which leads to the induction of apoptosis $(26-28,33,39,41)$. Many papers have shown that treatment of cell lines with pioglitazone and related TZDs can lead to specific apoptosis of glioma cells in a concentration-dependent fashion associated with cellcycle arrest, while sparing normal primary astrocytes (26-28, 33, 39, 41).

This effect could be mediated by BAX-dependent mechanisms, as BAX up-regulation is often detected via an increase in protein levels after activation of $\operatorname{PPAR} \gamma(25,27,39,41)$. Furthermore, studies have shown that transfection of cells with antisense oligonucleotides for $B A X$ nullified the effect of the PPAR $\gamma$ agonist treatment (39). Alternatively, BCL2 has been found to be down-regulated following administration of the same treatment $(25,27)$. Increases of protein activity of major executioner caspases CASP3 $(27,33,41)$ and CASP7 (33) have also 
been described in response to a PPAR $\alpha / \gamma$ dual agonist and troglitazone.

\section{CATALASE ACTIVITY}

Catalase is an enzyme involved in the neutralization of reactive oxygen species and its gene contains a PPAR genomic binding site (44). Studies have suggested that the cytotoxic effect of PPAR $\gamma$ agonists on glioma cells is partially mediated by enhanced redox reactions (44).

In in vitro rat cell models, activation of PPAR $\gamma$ transcription has been shown to upregulate catalase activity in normal astrocytes, but not in the glioma C6 cell line (44).Moreover, this effect was abolished in cells transfected with a dominant negative PPAR $\gamma$ construct (44).

This area requires further experimentation using human cell lines, as catalase could be a possible redox-dependent target for

Table 1 |A summary of the PPAR $y$ agonists referred to in this review and their current status with regards to clinical application.

\begin{tabular}{lll}
\hline $\begin{array}{l}\text { PPAR } \\
\text { agonist }\end{array}$ & Clinical use & Extra information \\
\hline Pioglitazone & $\begin{array}{l}\text { FDA-approved } \\
\text { for diabetes } \\
\text { mellitus type II }\end{array}$ & $\begin{array}{l}\text { Activates PPAR } \gamma \text { to increase insulin } \\
\text { sensitivity, also activates PPAR } \alpha \text { to alter }\end{array}$ \\
lipetabolism (46)
\end{tabular}

protection of normal astrocytes from the reactive oxygen species produced by intensive therapies such as radiation.

\section{LIMITING FACTORS}

Rosiglitazone and pioglitazone are currently the only TZDs FDAapproved for clinical use, summarized in Table 1. It has been found that use of certain thiazolidinediones in treatment of diabetes mellitus can increase risk of congestive heart failure, myocardial infarction, cardiovascular disease, bone loss, weight gain, and fluid retention. Meta-analysis of eight studies involving 945,286 patients found that compared to pioglitazone, rosiglitazone administration conferred an increased risk of overall mortality as well as heart failure and myocardial infarction (4). The findings of this meta-analysis and the issue of cardiovascular side-effects due to administration of rosiglitazone remains controversial, and this has lead to a dramatic reduction in its use in clinical treatment of diabetes (45) with some countries withdrawing it from the market altogether. Additionally the doses used experimentally to activate the antineoplastic effects mediated by PPAR $\gamma$ have been observed to be much higher than the doses used in treatment of diabetes, even with differences of orders of magnitude $(19,35)$. The constitutively high levels of PPAR $\gamma$ expression in adipose tissues (when compared to expression levels in the brain) raises the possibility of systemic adverse side-effects from off-target activation of the PPAR $\gamma$ pathway by TZDs in increased. The biological benefits and detrimental side-effects of PPAR $\gamma$ use in GBM are summarized in Figure 2.

In conclusion, we examined the biological rationale for the use of PPAR agonists in glioblastoma, in particular brain tumor growth inhibition, glioma cell differentiation, inhibition of apoptosis, and increased catalase activity. The potential for the use of these agents in this GBM may be limited by recently described side-effects in this group of agents, and the variation between expression levels of PPAR $\gamma$ in different tissues.

However, in patients with such a universal poor prognosis further investigation into this pathway is justified on the basis of preliminary epidemiological data. Advances in knowledge of the PPAR pathway in GBM may identify new cellular targets for brain tumor therapies.
Drawbacks

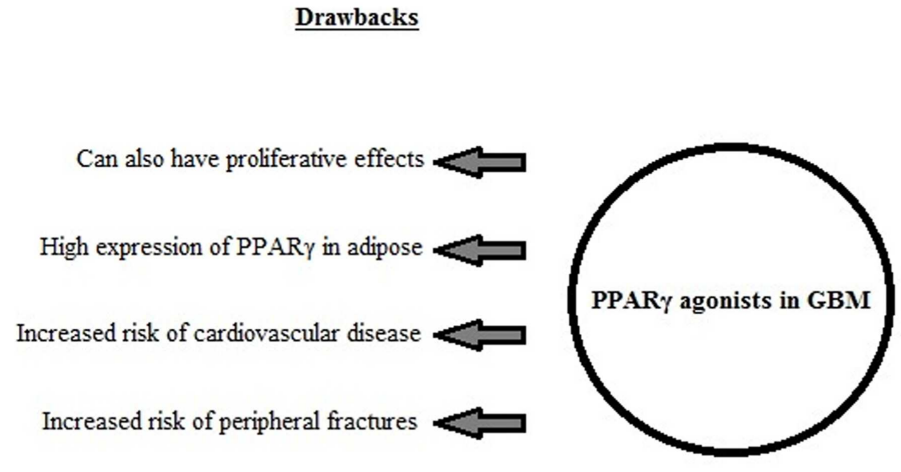

Benefits

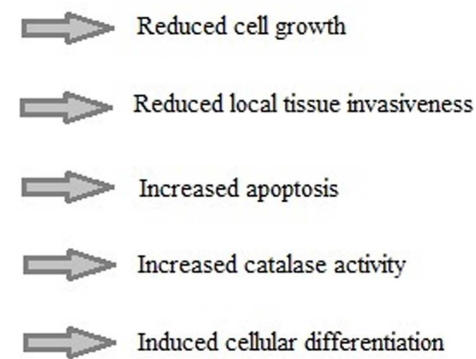

FIGURE 2 | A summary of the biological effects induced by PPAR $\gamma$ agonist use in GBM in vitro and in vivo, and the drawbacks associated with PPAR agonist use in clinical treatment of diabetes mellitus. 


\section{REFERENCES}

1. Siersbæk MS, Loft A, Aagaard MM, Nielsen R, Schmidt SF, Petrovic N, et al. Genome-wide profiling of peroxisome proliferator-activated receptor $\gamma$ in primary epididymal, inguinal, and brown adipocytes reveals depot-selective binding correlated with gene expression. Mol Cell Biol (2012) 32:3452-63. doi:10.1128/MCB.00526-12

2. Nielsen R, Mandrup S. Genome-wide profiling of transcription factor binding and epigenetic marks in adipocytes by ChIP-seq. Methods Enzymol (2014) 537:261-79. doi:10.1016/B978-0-12-411619-1.00014-8

3. Barish GD, Narkar VA, Evans RM. PPAR delta: a dagger in the heart of the metabolic syndrome. J Clin Invest (2006) 116:590-7. doi:10.1172/JCI27955

4. Forman BM, Tontonoz P, Chen J, Brun RP, Spiegelman BM, Evans RM. 15-Deoxy-delta 12, 14-prostaglandin J2 is a ligand for the adipocyte determination factor PPAR gamma. Cell (1995) 83:803-12. doi:10.1016/0092-8674(95) 90193-0

5. Ahmadian M, Suh JM, Hah N, Liddle C, Atkins AR, Downes M, et al. PPAR $\gamma$ signaling and metabolism: the good, the bad and the future. Nat Med (2013) 9:557-66. doi:10.1038/nm.3159

6. Lefterova MI, Steger DJ, Zhuo D, Qatanani M, Mullican SE, Tuteja G, et al. Cell-specific determinants of peroxisome proliferator-activated receptor gamma function in adipocytes and macrophages. Mol Cell Biol (2010) 30:2078-89. doi:10.1128/MCB.01651-09

7. Sérandour AA, Avner S, Oger F, Bizot M, Percevault F, Lucchetti-Miganeh C, et al. Dynamic hydroxymethylation of deoxyribonucleic acid marks differentiationassociated enhancers. Nucleic Acids Res (2012) 40:8255-65. doi:10.1093/nar/ gks595

8. Escher P, Braissant O, Basu-Modak S, Michalik L, Wahli W, Desvergne B. Rat PPARs: quantitative analysis in adult rat tissues and regulation in fasting and refeeding. J Endocrinol (2001) 142:4195-202. doi:10.1210/en.142.10.4195

9. Park K, Lee R, Kang S, Han S, Park K, Yang K, et al. Neuronal differentiation of embryonic midbrain cells by upregulation of peroxisome proliferatoractivated receptor-gamma via the JNK-dependent pathway. Exp Cell Res (2004) 297:424-33. doi:10.1016/j.yexcr.2004.03.034

10. Bugge A, Mandrup S. Molecular mechanisms and genome-wide aspects of PPAR subtype specific transactivation. PPAR Res (2010) 2010:169506. doi:10.1155/ 2010/169506

11. Grommes C, Conway D, Alshekhlee A, Barnholtz-Sloan J. Inverse association of PPAR gamma agonists use and high grade glioma development. J Neurooncol (2010) 100:233-9. doi:10.1007/s11060-010-0185-x

12. Zhou XP, Smith WM, Gimm O, Mueller E, Gao X, Sarraf P, et al. Overrepresentation of PPARgamma sequence variants in sporadic cases of glioblastoma multiforme: preliminary evidence for common low penetrance modifiers for brain tumour risk in the general population. J Med Genet (2000) 37:410-4. doi:10.1136/jmg.37.6.410

13. Sarraf P, Mueller E, Smith WM, Wright HM, Kum JB, Aaltonen LA, et al. Lossof-function mutations in PPAR gamma associated with human colon cancer. Mol Cell (1999) 3:799-804. doi:10.1016/S1097-2765(01)80012-5

14. Tsubouchi Y, Sano H, Kawahito Y, Mukai S, Yamada R, Kohno M, et al. Inhibition of human lung cancer cell growth by the peroxisome proliferator-activated receptor-gamma agonists through induction of apoptosis. Biochem Biophys Res Commun (2000) 270:400-5. doi:10.1006/bbrc.2000.2436

15. Mueller E, Smith M, Sarraf P, Kroll T, Aiyer A, Kaufman DS, et al. Effects of ligand activation of peroxisome proliferator-activated receptor gamma in human prostate cancer. Proc Natl Acad Sci U S A (2000) 97:10990-5. doi:10.1073/pnas. 180329197

16. Tseng $\mathrm{CH}$, Tseng FH. Peroxisome proliferator-activated receptor agonists and bladder cancer: lessons from animal studies. J Environ Sci Health C Environ Carcinog Ecotoxicol Rev (2012) 30:368-402. doi:10.1080/10590501. 2012.735519

17. Mueller E, Sarraf P, Tontonoz P, Evans RM, Martin KJ, Zhang M, et al. Terminal differentiation of human breast cancer through PPAR gamma. Mol Cell (1998) 1:465-70. doi:10.1016/S1097-2765(00)80047-7

18. Kroll TG, Sarraf P, Pecciarini L, Chen CJ, Mueller E, Spiegelman BM, et al. PAX8-PPARgammal fusion oncogene in human thyroid carcinoma [corrected]. Science (2000) 289:1357-60. doi:10.1126/science.289.5483.1357

19. Simula MP, Cannizzaro R, Canzonieri V, Pavan A, Maiero S, Toffoli G, et al. PPAR signaling pathway and cancer-related proteins are involved in celiac diseaseassociated tissue damage. Mol Med (2010) 16:199-209. doi:10.2119/molmed. 2009.00173
20. Tanaka T, Kohno H, Yoshitani S, Takashima S, Okumura A, Murakami A, et al. Ligands for peroxisome proliferator-activated receptors alpha and gamma inhibit chemically induced colitis and formation of aberrant crypt foci in rats. Cancer Res (2001) 61:2424-8.

21. Saez E, Tontonoz P, Nelson MC, Alvarez JG, Ming UT, Baird SM, et al. Activators of the nuclear receptor PPARgamma enhance colon polyp formation. Nat Med (1998) 4:1058-61. doi:10.1038/2042

22. Mansure JJ, Nassim R, Kassouf W. Peroxisome proliferator-activated receptor gamma in bladder cancer: a promising therapeutic target. Cancer Biol Ther (2009) 8:6-15. doi:10.4161/cbt.8.7.7853

23. Long GG, Reynolds VL, Dochterman LW, Ryan TE. Neoplastic and nonneoplastic changes in F-344 rats treated with naveglitazar, a gamma-dominant PPAR alpha/gamma agonist. Toxicol Pathol (2009) 37:741-53. doi:10.1177/ 0192623309343775

24. Lubet RA, Fischer SM, Steele VE, Juliana MM, Desmond R, Grubbs CJ. Rosiglitazone, a PPAR gamma agonist: potent promoter of hydroxybutyl(butyl)nitrosamine-induced urinary bladder cancers. Int $J$ Cancer (2008) 123:2254-9. doi:10.1002/ijc.23765

25. Zang C, Wächter M, Liu H, Posch MG, Fenner MH, Stadelmann C, et al. Ligands for PPARgamma and RAR cause induction of growth inhibition and apoptosis in human glioblastomas. J Neurooncol (2003) 65:107-18. doi:10.1023/B:NEON. 0000003728.80052.a8

26. Chearwae W, Bright JJ. PPARgamma agonists inhibit growth and expansion of CD133+ brain tumour stem cells. Br J Cancer (2008) 99:2044-53. doi:10.1038/sj.bjc.6604786

27. Liu D, Zang C, Liu H, Possinger K, Fan S, Elstner E. A novel PPAR alpha/gamma dual agonist inhibits cell growth and induces apoptosis in human glioblastoma T98G cells. Acta Pharmacol Sin (2004) 25:1312-9.

28. Wan Z, Shi W, Shao B, Shi J, Shen A, Ma Y, et al. Peroxisome proliferatoractivated receptor $\gamma$ agonist pioglitazone inhibits $\beta$-catenin-mediated glioma cell growth and invasion. Mol Cell Biochem (2011) 349:1-10. doi:10.1007/s11010010-0637-9

29. Mo C, Chearwae W, Bright JJ. PPARgamma regulates LIF-induced growth and self-renewal of mouse ES cells through Tyk2-Stat3 pathway. Cell Signal (2010) 22:495-500. doi:10.1016/j.cellsig.2009.11.003

30. Stechishin OD, Luchman HA, Ruan Y, Blough MD, Nguyen SA, Kelly JJ, et al. Ontarget JAK2/STAT3 inhibition slows disease progression in orthotopic xenografts of human glioblastoma brain tumor stem cells. J Neurooncol (2013) 15:198-207. doi:10.1093/neuonc/nos302

31. Vitale G, Zappavigna S, Marra M, Dicitore A, Meschini S, Condello M, et al. The PPAR- $\gamma$ agonist troglitazone antagonizes survival pathways induced by STAT3 in recombinant interferon- $\beta$ treated pancreatic cancer cells. Biotechnol $A d v$ (2012) 30:169-84. doi:10.1016/j.biotechadv.2011.08.001

32. Villalva C, Martin-Lannerée S, Cortes U, Dkhissi F, Wager M, Le Corf A, et al. STAT3 is essential for the maintenance of neurosphere-initiating tumor cells in patients with glioblastomas: a potential for targeted therapy? Int J Cancer (2011) 128:826-38. doi:10.1002/ijc.25416

33. Spagnolo A, Grant EN, Glick R, Lichtor T, Feinstein DL. Differential effects of PPARgamma agonists on the metabolic properties of gliomas and astrocytes. Neurosci Lett (2007) 417:72-7. doi:10.1016/j.neulet.2007.02.036

34. Ahmad I, Aykin-Burns N, Sim J, Walsh S, Higashikubo R, Buettner G, et al. Mitochondrial O-2(-center dot) and $\mathrm{H} 2 \mathrm{O} 2$ mediate glucose deprivation-induced cytotoxicity and oxidative stress in human cancer cells. J Biol Chem (2005) 280:4254-63. doi:10.1074/jbc.M411662200

35. Kanakasabai S, Pestereva E, Chearwae W, Gupta SK, Ansari S, Bright JJ. $\operatorname{PPAR} \gamma$ agonists promote oligodendrocyte differentiation of neural stem cells by modulating stemness and differentiation genes. PLoS One (2012) 7:e50500. doi:10.1371/journal.pone.0050500

36. Pestereva E, Kanakasabai S, Bright JJ. PPAR $\gamma$ agonists regulate the expression of stemness and differentiation genes in brain tumour stem cells. $\mathrm{Br}$ J Cancer (2012) 106:1702-12. doi:10.1038/bjc.2012.161

37. Schmitz M, Temme A, Senner V, Ebner R, Schwind S, Stevanovic S, et al. Identification of SOX2 as a novel glioma-associated antigen and potential target for T cell-based immunotherapy. Br J Cancer (2007) 96:1293-301. doi:10.1038/sj.bjc.6603696

38. Hendrickx M, Van X, Leyns L. Anterior-posterior patterning of neural differentiated embryonic stem cells by canonical Wnts, Fgfs, Bmp4 and their respective antagonists. Dev Growth Differ (2009) 51:687-98. doi:10.1111/j.1440-169X. 2009.01128.x 
39. Zander T, Kraus JA, Grommes C, Schlegel U, Feinstein D, Klockgether T, et al. Induction of apoptosis in human and rat glioma by agonists of the nuclear receptor PPARgamma. J Neurochem (2002) 81:1052-60. doi:10.1046/j.14714159.2002.00899.x

40. Papi A, Tatenhorst L, Terwel D, Hermes M, Kummer MP, Orlandi M, et al. PPARgamma and RXRgamma ligands act synergistically as potent antineoplastic agents in vitro and in vivo glioma models. J Neurochem (2009) 109:1779-90. doi:10.1111/j.1471-4159.2009.06111.x

41. Grommes C, Landreth GE, Sastre M, Beck M, Feinstein DL, Jacobs AH, et al. Inhibition of in vivo glioma growth and invasion by peroxisome proliferatoractivated receptor gamma agonist treatment. Mol Pharmacol (2006) 70:1524-33. doi:10.1124/mol.106.022194

42. Rao J, Steck P, Mohanam S, Stetlerstevenson W, Liotta L, Sawaya R. Elevated levels of M(R) 92,000 type-IV collagenase in human brain-tumours. Cancer Res (1993) 53:2208-11.

43. Liu X, Wang L, Zhao S, Ji X, Luo Y, Ling F. Beta-catenin overexpression in malignant glioma and its role in proliferation and apoptosis in glioblastma cells. Med Oncol (2011) 28:608-14. doi:10.1007/s12032-010-9476-5

44. Khoo NKH, Hebbar S, Zhao W, Moore SA, Domann FE, Robbins ME. Differential activation of catalase expression and activity by PPAR agonists: implications for astrocyte protection in anti-glioma therapy. Redox Biol (2013) 1:70-9. doi:10.1016/j.redox.2012.12.006

45. Ajjan RA, Grant PJ. The cardiovascular safety of rosiglitazone. Expert Opin Drug Saf (2008) 7:367-76. doi:10.1517/14740338.7.4.367

46. Gillies PS, Dunn CJ. Pioglitazone. Drugs (2000) 60:333-43. doi:10.2165/ 00003495-200060020-00009

47. Chen X, Yang L, Zhai SD. Risk of cardiovascular disease and all-cause mortality among diabetic patients prescribed rosiglitazone or pioglitazone: a meta-analysis of retrospective cohort studies. Chin Med J (Engl) (2012) 125:4301-6.

48. Aljada A, Garg R, Ghanim H, Mohanty P, Hamouda W, Assian E, et al. Nuclear factor-kappaB suppressive and inhibitor-kappaB stimulatory effects of troglitazone in obese patients with type 2 diabetes: evidence of an antiinflammatory action? J Clin Endocrinol Metab (2001) 86:3250-6. doi:10.1210/jc.86.7.3250

49. Hulin B, Newton LS, Lewis DM, Genereux PE, Gibbs EM, Clark DA. Hypoglycemic activity of a series of alpha-alkylthio and alpha-alkoxy carboxylic acids related to ciglitazone. J Med Chem (1996) 39:3897-907. doi:10.1021/jm960230h

50. Scher JU, Pillinger MH. 15d-PGJ2: the anti-inflammatory prostaglandin? Clin Immunol (2005) 114:100-9. doi:10.1016/j.clim.2004.09.008

Conflict of Interest Statement: The authors declare that the research was conducted in the absence of any commercial or financial relationships that could be construed as a potential conflict of interest.

Received: 29 January 2014; accepted: 03 March 2014; published online: 14 March 2014. Citation: Ellis HP and Kurian KM (2014) Biological rationale for the use of PPAR $\gamma$ agonists in glioblastoma. Front. Oncol. 4:52. doi: 10.3389/fonc.2014.00052

This article was submitted to Cancer Endocrinology, a section of the journal Frontiers in Oncology.

Copyright (C) 2014 Ellis and Kurian. This is an open-access article distributed under the terms of the Creative Commons Attribution License (CC BY). The use, distribution or reproduction in other forums is permitted, provided the original author(s) or licensor are credited and that the original publication in this journal is cited, in accordance with accepted academic practice. No use, distribution or reproduction is permitted which does not comply with these terms. 